\title{
Bioequivalence Study of 1,500 mg Glucosamine Sulfate in Thai Healthy Volunteers
}

\author{
Pravit Akarasereenont*, Somruedee Chatsiricharoenkul and Piyapat Pongnarin
}

Department of Pharmacology, Faculty of Medicine Siriraj Hospital, Mahidol University, Thailand

\begin{abstract}
Glucosamine sulfate is widely used to relieve symptoms from osteoarthritis. This study was conducted in order to determine pharmacokinetic and assessed the in-vivo bioequivalence of two different hard capsule formulations of glucosamine sulfate when administered as equal dose of $1,500 \mathrm{mg}$. The two formulations contain different salt form where reference product is $\mathrm{NaCl}$ and test product is $\mathrm{KCl}$. A randomized, single dose, two-treatment, twoperiod, two-sequence crossover study was conducted. Twenty-six healthy volunteers were recruited at Siriraj Clinical Research Unit. Each subject received a dose of $1,500 \mathrm{mg}$ glucosamine sulfate of both formulations with at least a week washout period. Blood samples were collected over $24 \mathrm{hrs}$ after the oral administration. The plasma fractions were analyzed for glucosamine using LC-MS/MS. Twenty-six volunteers enrolled in the present study. Pharmacokinetic parameters were determined using the non-compartment model. The $90 \%$ confidence intervals of the mean ratios (test/reference) of $C_{\text {max }}(111.19 \%$; ranged from $93.01 \%-132.92 \%)$ and $A U C_{0 . t}(107.24$; ranged from $87.16 \%-131.93 \%$ ) was not contained within the equivalence criteria of $80.00-125.00 \%$ (USFDA, 2003). However, this study showed the high intra-individual CV calculated from ANOVA for $\mathrm{C}_{\max }$ and $A \cup \mathrm{C}_{024}(\geq 30 \%)$. Thus, based on equivalence limits of USFDA (2003), the test product is not bioequivalent to the reference product in terms of rate and extent of absorption. However, concerning the wider equivalence criteria for highly variable drug (EMEA, 2008), the test product is bioequivalent to the reference formulation in terms of rate and extent of absorption.
\end{abstract}

Keywords: Glucosamine; LCMS/MS; Bioequivalence; Pharmacokinetic Introduction

Several clinical studies have indicated that glucosamine sulphate is effective in controlling osteoarthritis (OA) symptoms and disease progression [1-4]. In particular, two randomised, placebo-controlled, double-blind trials of 3-year duration in knee osteoarthritis (OA) patients, showed that this symptom-modifying effect is sustained over long-term treatment courses $[5,6]$. Moreover, many studies suggested that the drug also has a structure-modifying effect, as assessed by measurement of joint space narrowing using validated techniques on standardised plain radiographs [4,5,7-9]. Another recently completed trial (the GUIDE study) [10], confirmed the symptomatic results described above and indicated that, at the dose of $1500 \mathrm{mg}$ once-a-day, crystalline glucosamine sulphate provided a symptomatic effect that was significantly superior to that observed after the administration of placebo [11]. On the other, some studies did not detect any benefit of glucosamine $[12,13]$.

The formulation used in several studies $[4,7,10]$ is the original crystalline glucosamine sulphate $1,500 \mathrm{mg}$ once-a-day soluble powder preparation which is a prescription drug in most European and extraEuropean countries [11]. However, in United States, glucosamine is marketed as a dietary supplement to enhance the repair and synthesis of cartilage and connective tissue. It is reported that the U.S. retail market for nutritional supplements containing glucosamine or chondroitins is more than $\$ 1$ billion per year; the demand for bulk glucosamine has been growing in excess of $20 \%$ annually, and global consumption exceeds 5000 metric tons [14].

Our previous studies [15] show that glucosamine sulfate containing $\mathrm{KCl}$ (500 mg capsule) is bioequivalent to glucosamine sulfate containing $\mathrm{NaCl}(2 \times 250 \mathrm{mg}$ capsules $)$ in terms of rate and extent of absorption. This study is designed to evaluate the quality of the generic sachet formulation of glucosamine sulfate $1,500 \mathrm{mg}$ in compare with the original formulation, Viartril ${ }^{\mathbb{B}}-\mathrm{S}$. The dosage of glucosamine sulfate $1,500 \mathrm{mg}$ for both formulations were administered as a single dose to 26 healthy volunteers under a two-treatment, two-period, and twosequence crossover study design with a minimum of one week washout period.

\section{Materials and Methods}

\section{Glucosamine preparations}

Test preparation: Flexsa ${ }^{\circledR}$ (Mega Lifesciences Company Ltd. Thailand) containing $1,500 \mathrm{mg}$ glucosamine sulfate $\mathrm{KCl}$ powder for oral solution in sachet (Lot no. 8185, Mfg. date February 2007, Exp. date February 2009).

Reference preparation: Viartril ${ }^{\circledR}$-S (Rottapharm Company Ltd., Ireland) containing $1,500 \mathrm{mg}$ glucosamine sulfate $\mathrm{NaCl}$ powder for oral solution in sachet (Lot no. G07043A, Mfg. date 12 February 2007, Exp. date 28 February 2010).

\section{Volunteers}

Twenty-six healthy Thai volunteers aged between 18-45 years with a body mass index between $18-25 \mathrm{~kg} / \mathrm{m}^{2}$ were recruited at Siriraj Clinical Research Center, Siriraj Hospital. After explaining the details

*Corresponding author: Pravit Akarasereenont, Department of Pharmacology, Faculty of Medicine Siriraj Hospital, Mahidol University, Prannok Rd, Bangkok 10700 Thailand, Tel: 66-2-4197569; Fax: 66-2-4181297; E-mail: sipak@mahidol.ac.th

Received June 21, 2012; Accepted August 16, 2012; Published August 20, 2012

Citation: Akarasereenont P, Chatsiricharoenkul S, Pongnarin P (2012) Bioequivalence Study of $1,500 \mathrm{mg}$ Glucosamine Sulfate in Thai Healthy Volunteers. J Bioequiv Availab 4: 091-095. doi:10.4172/jbb.1000119

Copyright: () 2012 Akarasereenont P, et al. This is an open-access article distributed under the terms of the Creative Commons Attribution License, which permits unrestricted use, distribution, and reproduction in any medium, provided the original author and source are credited. 
and the purposes of the present study, all healthy volunteers provided written informed consents. They were non-smoking, non-alcoholic, and free from significant cardiac, hepatic, renal, gastrointestinal, and hematological diseases, as assessed by physical examination and the following laboratory investigations: complete blood count, BUN, creatinine, aspartate aminotransferase, alanine aminotransferase, total bilirubin, alkaline phosphatase, fasting blood sugar, serum electrolyte and hepatitis B surface antigen. Urine pregnancy tests were negative in all female volunteers. Volunteers did not have a history of allergy to glucosamine and/or its constituents and did not receive other medicines within 14 days before the first study drug administration.

\section{Study design}

Randomized, single dose, fasting, two-period, two-sequence; crossover study with at least one week washout period was conducted. Volunteers were allocated into two equal groups. Each volunteer was assigned to a particular study group using a pre-printed randomization table generated by Microsoft Excel. During each period, the volunteers were admitted to the Siriraj Clinical Research Center, Siriraj Hospital. After overnight fasting for at least 8 hours, they received a single dose of test formulation (1,500 $\mathrm{mg}$ sachet) or reference formulation (1,500 mg sachet) along with $240 \mathrm{ml}$ of drinking water. Volunteers continued fasting for 2 and 4 hrs (water and food, respectively) after drug administration.

The subjects were closely observed to assess the adverse events. As test product containing $\mathrm{KCl} 6.58 \mathrm{mmol} / 1,500 \mathrm{mg}$, serum potassium was monitored at pre-dose, 12 and $24 \mathrm{hrs}$ after test and reference products administration.

The study was approved by the independent Ethics Committee of Faculty of Medicine, Siriraj Hospital, Mahidol University prior to commencing and was performed in accordance with the Declaration of Helsinki and Good Clinical Practice Guideline. All subjects were individually given written informed consent prior to starting study procedures.

\section{Sample collection and glucosamine analysis}

Nine $\mathrm{ml}$ of each blood sample was collected by catheterized venupuncture at forearms from each subject. Sodium heparinized vacutainer tubes were used for sample collection. Thirteen samples were collected: 0 (before the dosing), 10, 20, $30 \mathrm{~min}$ and 1, 1.5, 2, $3,4,6,8,12$ and $24 \mathrm{~h}$ after administration. The blood samples were centrifuged. Then, the plasma fractions were collected and kept at $-70^{\circ} \mathrm{C}$ until analysis.

Bioanalytical of plasma glucosamine was performed by using a validated high performance liquid chromatography with tandem mass spectrometry (HPLC-MS/MS) method in accordance with the USFDA guidelines [16]. Sample preparation was extracted by liquidliquid extraction technique. Propanolol Hydrochloride was used as an internal standard $(10 \mu \mathrm{g} / \mathrm{ml})$. Briefly, $10 \mu \mathrm{l}$ of internal standard was added in $500 \mu \mathrm{l}$ of standard spiked sample (Calibrators and QC sample) and plasma unknown sample and then was mixed for 10 seconds. After well mixed, all samples were added and mixed with 1,000 $\mu \mathrm{l}$ of extract solvent (a mixture of acetronitrile and triethylamine, 3:1 (v/v)). Then, the samples were centrifuged at $10,000 \mathrm{rpm}$ for $10 \mathrm{~min}$. The organic layer was transferred into a new vial. All of organic phase was evaporated to dryness under nitrogen gas. The residual was re-dissolved with a dilution solvent (triethylamine : acetonitrile, $10: 90(\mathrm{v} / \mathrm{v}))$ and injected into the LC-MS/MS system. The chromatographic separation was carried out on LC-MS/MS with C18, $2.5 \mu \mathrm{m}(50 \times 3.00 \mathrm{~mm}$ i.d.). A mobile phase consisting of acetonitrile and $0.025 \%$ formic acid (Gradient condition) was delivered with a flow rate of $0.2 \mathrm{ml} / \mathrm{min}$. Mass spectra were obtained using a Quattro Micro" mass spectrometer (Micromass Technologies, UK) equipped with electrospray ionisation (ESI) source in positive mode. The mass transition ion-pair for glucosamine $[M+\mathrm{H}]$ ${ }^{+}$ions was selected as $m / z 179.90>161.71$ and $179.90>143.70$. The mass transition ion-pair for propanolol $[M+\mathrm{H}]^{+}$ions was selected as $\mathrm{m} / \mathrm{z}$ $260.00>116.00$. The data acquisition was ascertained by Masslynx 4.0 software. All validated results of our new developed LC-MS/MS method were found in the acceptable limit criteria of US FDA guidance with exhibit good accuracy and reproducibility. Calibration curve was linearity in the range of $0.05-10 \mu \mathrm{g} / \mathrm{mL}$. The best linear fit was achieved with a $1 / \mathrm{x}$ weighting factor, showing a mean correlation coefficient $\left(r^{2}\right)$ $\geq 0.999800$. The lower limit of quantification (LLOQ) for the validated assay was $0.05 \mu \mathrm{g} / \mathrm{ml}$. The limit of detection (LOD) was $0.0075 \mu \mathrm{g} /$ ml. Mean recovery of extraction were $89.83-96.99 \%$ and $106.45 \%$ for glucosamine and internal standard, respectively. The intra- and interassay precision was $0.84 \%-9.79 \%$ and $1.20-3.49 \%$, respectively. The percentage average of intra- and inter-assay accuracy was between 93.65\%-102.67\% and $97.25 \%-101.41 \%$, respectively. The stability of glucosamine in plasma during sample processing at room temperature after 6 hours for short term stability and 30 days storage in $-70^{\circ} \mathrm{C}$ for long term stability was within the acceptable limit of standard criteria. The $\%$ of variation of glucosamine for post-preparative stability was also showing no significant loss in the quantified values, indicating that samples should be processed within this period of time (10 hours.)

\section{Pharmacokinetic and statistical analysis}

A non-compartmental pharmacokinetic model was used to determine the pharmacokinetic parameters of glucosamine. The pharmacokinetic parameters, i.e., $\mathrm{AUC}_{0 \rightarrow \mathrm{t}}, \mathrm{AUC}_{0 \rightarrow \infty}, \mathrm{C}_{\max }, \mathrm{t}_{\max }, \mathrm{t}_{1 / 2}$ were determined using WinNonlin edition version 3.1. Statistical comparisons between pharmacokinetic parameters of the two products were analyzed using two-way ANOVA with $\mathrm{p}<0.05$ for statistical significance to assess the effect of formulation, periods, sequence, subjects within sequence. The variation in estimation of terminal slope as can be seen in lamda_z or $t_{1 / 2}$ calculation (0.693/lamda_z), the $\mathrm{AUC}_{0 \rightarrow \infty}$ might not be a good parameter to be compared. Moreover, our first previous bioanalytical method was not sensitive enough to detect the concentration of glucosamine. There are many BQL data even also at baseline level. Thus, it may not be possible to obtain reliable $\mathrm{AUC}_{0 \rightarrow \infty}$ parameters. Thus, we did the statistical analysis for $\mathrm{AUC}_{0 \rightarrow t}$ instead. The 90 percent confidence intervals of the test/reference ratio of $\mathrm{C}_{\max }$, and $\mathrm{AUC}_{0 \rightarrow \mathrm{t}}$ using $\log$ transformed data were determined. The bioequivalence between the two formulations would be accepted if the 90 percent confidence intervals $(\mathrm{CI})$ of the log transformed $\mathrm{C}_{\max }$, and $\mathrm{AUC}_{0 \rightarrow \mathrm{t}}$ of test fell within $80-125 \%$ of the original product [17].

\section{Results and Discussion}

Twenty-six volunteers (13 males, 13 females) completed the study. Demographic characteristics of subjects among 2 groups seemed similar and shown in Table 1. The average plasma concentrations of at each time point from 26 Healthy Volunteers after administration of the reference and test product are tabulated in Table 2. No significant difference was observed in any of the analyzed pharmacokinetic parameters (Table 3 ). The geometric mean for test $t 1 / 2$ is 15.650 and that for reference is 23.231 which show less different. Because the distribution of $\mathrm{t} 1 / 2 \mathrm{might}$ not be a normal distribution, it may be better to use to geometric mean 
Citation: Akarasereenont P, Chatsiricharoenkul S, Pongnarin P (2012) Bioequivalence Study of 1,500 mg Glucosamine Sulfate in Thai Healthy Volunteers. J Bioequiv Availab 4: 091-095. doi:10.4172/jbb.1000119

\begin{tabular}{|c|c|c|c|}
\hline \multicolumn{2}{|c|}{ Characteristics } & \multirow{2}{*}{$\begin{array}{c}\begin{array}{c}\text { Group } 1 \\
\text { (TR Group) } \\
(n=13)\end{array} \\
5 \\
8\end{array}$} & \multirow{2}{*}{$\begin{array}{c}\begin{array}{c}\text { Group } 2 \\
\text { (RT Group) } \\
\text { ( } n=13)\end{array} \\
8 \\
5\end{array}$} \\
\hline Gender & $\begin{array}{c}\text { Male } \\
\text { Female }\end{array}$ & & \\
\hline Age (years \pm SD)) & & $25 \pm 4.8$ & $25.4 \pm 5.4$ \\
\hline Weight (kg. \pm SD) & & $60.3 \pm 8.3$ & $59.3 \pm 8.8$ \\
\hline Height (cm. \pm SD) & & $170.4 \pm 8.3$ & $168.8 \pm 6.6$ \\
\hline Body Mass Index $\left(\mathrm{kg} / \mathrm{m}^{2} \pm \mathrm{SD}\right)$ & & $20.7 \pm 1.8$ & $20.7 \pm 2.1$ \\
\hline Vital signs & $\begin{array}{c}\text { Temperature }\left({ }^{\circ} \mathrm{C} \pm \mathrm{SD}\right) \\
\text { Pulse (beat/minutes } \pm \mathrm{SD}) \\
\text { Respiratory Rate (times } / \text { minute } \pm \mathrm{SD}) \\
\text { Systolic Blood Pressure }(\mathrm{mmHg} \pm \mathrm{SD}) \\
\text { Diastolic Blood Pressure }(\mathrm{mmHg} \pm \mathrm{SD})\end{array}$ & $\begin{array}{c}36.7 \pm 0.2 \\
69.2 \pm 12.6 \\
19.9 \pm 0.3 \\
110.1 \pm 10.2 \\
69.7 \pm 9.2\end{array}$ & $\begin{array}{c}36.8 \pm 0.2 \\
70.1 \pm 9.2 \\
19.2 \pm 1.5 \\
105.4 \pm 10.8 \\
69.3 \pm 12.2\end{array}$ \\
\hline Clinical laboratory & $\begin{array}{c}\text { Hemoglobin }(\mathrm{g} / \mathrm{dl}) \\
\text { Hematocrit }(\%) \\
\text { BUN (mg/dl) } \\
\text { Creatinine (mg/dl) } \\
\text { AST(units/L) } \\
\text { ALT(units/L) } \\
\text { ALP(units/L) } \\
\text { LDH(units/L) } \\
\text { Total bilirubin (mg/dL) }\end{array}$ & $\begin{array}{c}13.9 \pm 1.2 \\
41.9 \pm 3.6 \\
9.8 \pm 2.1 \\
0.8 \pm 0.1 \\
21.2 \pm 4.9 \\
16.5 \pm 5.0 \\
63.7 \pm 21.2 \\
279.4 \pm 41.7 \\
0.7 \pm 0.3\end{array}$ & $\begin{array}{c}13.9 \pm 1.6 \\
41.7 \pm 4.8 \\
12.0 \pm 2.4 \\
0.8 \pm 0.2 \\
20.2 \pm 3.9 \\
15.9 \pm 4.4 \\
60.4 \pm 20.5 \\
294.4 \pm 36.3 \\
0.7 \pm 0.4\end{array}$ \\
\hline Serum electrolyte & $\begin{array}{l}\text { Blood sugar }(\mathrm{mg} / \mathrm{dL}) \\
\qquad \begin{array}{l}\mathrm{Na}+(\mathrm{mmol} / \mathrm{L}) \\
\mathrm{K}+(\mathrm{mmol} / \mathrm{L}) \\
\mathrm{Cl}-(\mathrm{mmol} / \mathrm{L}) \\
\mathrm{HCO} 3-(\mathrm{mmol} / \mathrm{L})\end{array}\end{array}$ & $\begin{array}{c}79.1 \pm 7.3 \\
139.85 \pm 0.95 \\
4.05 \pm 0.19 \\
103.38 \pm 1.82 \\
27.31 \pm 1.59\end{array}$ & $\begin{array}{c}82.2 \pm 5.4 \\
140.08 \pm 1.51 \\
4.09 \pm 0.29 \\
101.92 \pm 2.02 \\
28.92 \pm 2.81\end{array}$ \\
\hline
\end{tabular}

Table 1: Demographic Data and Mean clinical laboratory of 26 Volunteers.

\begin{tabular}{|c|c|c|}
\hline Time (Hr) & Mean \pm S.D. $(\boldsymbol{\mu g} / \mathrm{ml})$ & \\
\hline $0 \mathrm{~min}$ & Test Product & Reference Product \\
\hline $10 \mathrm{~min}$ & $0.3926 \pm 0.3010$ & $0.3977 \pm 0.3902$ \\
\hline $20 \mathrm{~min}$ & $1.3282 \pm 0.7588$ & $0.7498 \pm 0.5054$ \\
\hline $30 \mathrm{~min}$ & $2.3212 \pm 1.0313$ & $2.1334 \pm 1.0920$ \\
\hline $1 \mathrm{hr}$ & $3.5808 \pm 1.8990$ & $3.1109 \pm 1.8677$ \\
\hline $1.5 \mathrm{hr}$ & $3.9149 \pm 1.8257$ & $4.1001 \pm 2.5635$ \\
\hline $2 \mathrm{hr}$ & $4.3860 \pm 2.5859$ & $4.4126 \pm 2.5472$ \\
\hline $3 \mathrm{hr}$ & $4.3759 \pm 3.6053$ & $3.8045 \pm 2.5497$ \\
\hline $4 \mathrm{hr}$ & $3.5139 \pm 3.0156$ & $3.1042 \pm 2.5472$ \\
\hline $6 \mathrm{hr}$ & $1.4454 \pm 1.0619$ & $1.2028 \pm 0.8092$ \\
\hline $8 \mathrm{hr}$ & $0.7346 \pm 0.4929$ & $0.8093 \pm 0.4353$ \\
\hline $12 \mathrm{hr}$ & $0.4910 \pm 0.4152$ & $0.4998 \pm 0.2874$ \\
\hline $24 \mathrm{hr}$ & $0.5733 \pm 0.4504$ & $0.3938 \pm 0.1627$ \\
\hline
\end{tabular}

Table 2: Average Plasma Concentration of Glucosamine from 26 Healthy Volunteers after Administration of Test and Reference Product.

for more log-normal distribution. The generic formulation had $\mathrm{C}_{\max }$ at $0.99 \mu \mathrm{g} / \mathrm{ml}, \mathrm{t}_{\max }$ at $1.42 \mathrm{hrs}$ while the original formulation had $\mathrm{C}_{\max }$ at $1.12 \mu \mathrm{g} / \mathrm{ml}, \mathrm{t}_{\max }$ at $2.00 \mathrm{hrs}$ (Table 1 ). Ninety percent CI of the mean ratios (generic/original) of the log transformed of the $\mathrm{C}_{\max }$ and $\mathrm{AUC}_{0 \rightarrow \mathrm{t}}$ were $93.69 \%$ (ranged from $86.68 \%-113.32 \%$ ) and $97.73 \%$ (ranged from $87.38 \%-112.62 \%$ ), respectively. Since the $90 \% \mathrm{CI}$ for $\mathrm{C}_{\max }$ and $\mathrm{AUC}_{0 \rightarrow \mathrm{t}}$ fell within the predefined bioequivalence acceptance limits (80-125\% of the innovator); the generic and original formulations were considered bioequivalent in terms of the rate and extent of absorption.

The plots of average plasma concentration of glucosamine (ng/ml; mean \pm SD) $v$ s time over $24 \mathrm{hrs} \mathrm{sampling} \mathrm{period} \mathrm{after} \mathrm{oral} \mathrm{administration}$ of $500 \mathrm{mg}$ of the test and reference capsules are presented in Figure 1. It was found that the plasma profiles of the glucosamine concentration of both formulations exhibited closely similar patterns, which were nearly super imposable. The amounts of glucosamine in plasma at pre-dose were detected by the fact that glucosamine is a normal constituent of the extracellular matrix of mammalian articular cartilage and synovial fluid, and, therefore, endogenous concentrations of glucosamine may be present in blood as a result of this and other connective tissue turnover.

Glucosamine was well tolerated. The clinical tolerability was good with both formulations. No serious adverse events were registered in the course of the trial. For effects of potassium contained in test product, most of subjects (87.50\%) have normal level of serum potassium (3.5$5.0 \mathrm{mmol} / \mathrm{L}$ ). Two adverse events of hypokalemia (once after taking

\begin{tabular}{|c|c|c|c|}
\hline \multirow{2}{*}{$\begin{array}{l}\text { Pharmacokinetic } \\
\text { Parameters }\end{array}$} & \multicolumn{2}{|c|}{ Product (Mean) } & \multirow{2}{*}{$\begin{array}{c}90 \% \text { confidence interval }(\mathrm{Cl}) \\
\text { of the mean ratios (genericl } \\
\text { original) of log transformed } \\
\text { values }\end{array}$} \\
\hline & $\begin{array}{c}\text { Reference } \\
\text { (Viartril }^{\circledast}-\mathrm{S} \text { ) }\end{array}$ & $\begin{array}{c}\text { Test } \\
\left.\text { (Flexsa }{ }^{\circledast}\right)\end{array}$ & \\
\hline$t_{\max }(h)$ & 2.00 & 1.50 & - \\
\hline$t_{1 / 2}^{\max }(h)$ & 6.46 & 3.64 & - \\
\hline $\mathrm{C}_{\max }(\mu \mathrm{g} / \mathrm{ml})$ & 4.51 & 4.95 & $111.19 \%(93.01 \%-132.92 \%)$ \\
\hline $\mathrm{AUC}_{0 \rightarrow}{ }_{\infty}(\mathrm{obs})(\mu \mathrm{g} . \mathrm{h} / \mathrm{ml})$ & 23.1 & 22.8 & $98.64 \%(78.77 \%-123.52 \%)$ \\
\hline $\mathrm{AUC}_{0 \rightarrow 24}(\mu \mathrm{g} \cdot \mathrm{h} / \mathrm{ml})$ & 19.7 & 21.0 & $107.24 \%(87.16 \%-131.93 \%)$ \\
\hline
\end{tabular}

$\mathrm{t}_{\text {max }}=$ Time to reach the peak plasma concentration (presented as median (range)); $\mathrm{t}_{1 / 2}=$ Elimination half-life; $\mathrm{C}_{\max }=$ Maximal plasma observed concentration; $\mathrm{AUC}_{0}$ ${ }_{1 / 2}^{\infty}=$ Ars) $=$ Area under the concentration time curve form time zero to infinity; $\mathrm{AUC}_{0-24}=$ Area under the concentration-time curve from time zero to $24 \mathrm{hrs}$, where plasma concentration can be measured

Table 3: Pharmacokinetic parameters of Reference (Viartri $\left.{ }^{\otimes}-S\right)$ and Test (Flexsa ${ }^{\circledR}$ ) with $90 \%$ confidence interval $(\mathrm{Cl})$ of the mean ratios (generic/original) of log transformed values. 


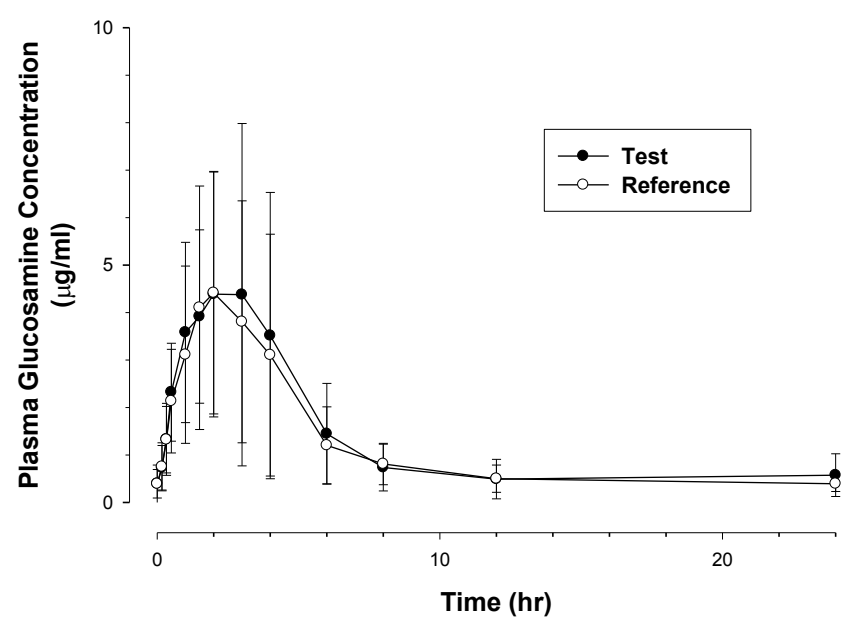

Figure 1: Average plasma concentration ( $\mu \mathrm{g} / \mathrm{mL}$; mean $\pm \mathrm{SD}$ ) vs time curves of glucosamine after oral administration of $1,500 \mathrm{mg}$ of the test $(\cdot)$ and reference capsules (०).

reference product and once after taking test product) and one event of dizziness (after taking test formulation) were reported in 3 volunteers. There were no clinically significant found and these three subjects received appropriate treatment and finally recovered. All of the adverse events were judged to be mild in intensity and were possibly related to the study drug. These events were also reported to Ethics Committee of Faculty of Medicine Siriraj Hospital, Mahidol University.

\section{Conclusions}

The bioequivalence study of two formulations of glucosamine sachet between the test product (Flexsa $\left.{ }^{\circledR}-1500\right)$ and the reference product (Viartril ${ }^{\circledR}$-S Sachet) in 25 healthy male and female volunteers was completed. This study was unbalanced and the ANOVA type III was calculated which demonstrated no significant sequence and treatment effects for all parameters. There was no significant period effect for $\mathrm{AUC}_{0-\infty \text { (obs) }}$ but there were significant period effect for $\mathrm{C}_{\max }$ and $\mathrm{AUC}_{0-24}$. Moreover, subject nested in sequence effect was significant for all parameters that may be due to the fact that the bioequivalence was performed in small sample size. Non-parametric Friedman's test for $\mathrm{T}_{\max }$ was demonstrated no significantly different between both formulations ( $p>0.05$ ). The $90 \%$ confidence interval of the geometric mean ratio (test/reference) of $\mathrm{C}_{\max }, \mathrm{AUC}_{0-24}$ and $\mathrm{AUC}_{0}$ $\infty$ (obs) was not contained within the equivalence criteria of 80.00 $125.00 \%$ [18]. However, this study showed the high intra-individual $\mathrm{CV}$ calculated from ANOVA for $\mathrm{C}_{\max }, \mathrm{AUC}_{0-24}$ and $\mathrm{AUC}_{0-\infty}$ that may be due to the fact that glucosamine is endogenous substance which those concentration varied considerably between individuals (high intersubject variability), especially between women $[19,20]$. Therefore, it can be indicated that glucosamine sulfate is a "highly variable drug" because a within subject variability of $\geq 30 \%$ in terms of the ANOVACV [21]. Based on the bioequivalence limit of highly variable drugs [22-24], it is acceptable for widening of confidence interval from $80.00 \%-125.00 \%$ to $75.00 \%-133.00 \%$ for $\mathrm{C}_{\max }$ parameter. Therefore, it is reasonable to be accepting that $\mathrm{C}_{\max }$ was entirely within equivalence limits of $75.00 \%-133.00 \%$. Moreover, a wider range of AUC may be acceptable [25] since glucosamine occurs naturally in human tissues and results of previous studies show the very well tolerability profile [4-5]. Using this guideline, the $90 \% \mathrm{CI}$ for $\mathrm{AUC}_{0-24}$ and $\mathrm{AUC}_{0-\infty}$ (obs) ratios were also within the acceptance bioequivalence range of $75.00 \%$ -
133.00\%. Thus, Based on equivalence limits of USFDA [18], it can be concluded that the test product is not bioequivalent to the reference product in terms of rate and extent of absorption. However, concerning the wider equivalence criteria for highly variable drug [22-24], it may be accepted that the test product was bioequivalent to the reference formulation in terms of rate and extent of absorption.

\section{Acknowledgement}

The authors would like to thanks Dr. Adisak Wongkajornsilp, Dr. Korbtham Sathirakul and Mr. Pipat Phetruengrong for bio-analysis and Ms. Patcharaporn Manopinives for kindly preparing manuscript.

\section{References}

1. Muller-Fassbender H, Bach GL, Haase W, Rovati LC Setnikar I (1994) Glucosamine sulfate compared to ibuprofen in osteoarthritis of the knee. Osteoarthritis Cartilage 2: 61-69.

2. Thie NM, Prasad NG, Major PW (2001) Evaluation of glucosamine sulfate compared to ibuprofen for the treatment of temporomandibular joint osteoarthritis: a randomized double blind controlled 3 month clinical trial. J Rheumatol 28: 1347-1355.

3. Towheed T, Maxwell L, Anastassiades TP, Shea B, Houpt JB, et al. (2005) Glucosamine therapy for treating osteoarthritis. Cochrane Database Systemic Review.

4. Reginster JY, Deroisy R, Rovati LC, Lee RL, Lejeune E, et al. (2001) Long-term effects of glucosamine sulphate on osteoarthritis progression: a randomised placebo-controlled clinical trial. Lancet 357: 251-256.

5. Bruyere O, Pavelka K, Rovati LC, Deroisy R, Olejarova M, et al. (2004) Glucosamine sulfate reduces osteoarthritis progression in postmenopausa women with knee osteoarthritis: evidence from two 3-year studies. Menopause 11: 138-143.

6. Noack W, Fischer M, Forster KK, Lucio C. Rovati, Ivo Setnikar, et al. (1994) Glucosamine sulfate in osteoarthritis of the knee. Osteoarthritis and Cartilage 2: 51-59.

7. Pavelka K, Gatterova J, Olejarova M, Machacek S, Giacovelli G, et al. (2002) Glucosamine sulfate use and delay of progression of knee osteoarthritis: a 3-year, randomized, placebo-controlled, double-blind study. Arch Intern Med 162: 2113-2123.

8. Bazian Ltd (2005) Glucosamine for osteoarthritis. Evidence-Based Healthcare and Public Health 9: 322-331.

9. Poolsup N, Suthisisang C, Channark P, Kittikulsuth W (2005) Glucosamine long-term treatment and the progression of knee osteoarthritis: systematic review of randomized controlled trials. Ann Pharmacother 39: 1080-1087.

10. Herrero-Beaumont G, Román JA, Trabado MC, et al. (2005) Effects of glucosamine sulfate on 6-month control of knee osteoarthritis symptoms vs placebo and acetaminophen: Results from the glucosamine unum in die efficacy (GUIDE) trial. Osteoarthritis and Cartilage (Suppl 1): S13.

11. Persiani S, Rotini R, Trisolino G, Rovati LC, Locatelli M, et al. (2007) Synovia and plasma glucosamine concentrations in osteoarthritic patients following ora crystalline glucosamine sulphate at therapeutic dose. Osteoarthritis Cartilage 15: $764-772$

12. Hughes R, Carr A (2002) A randomized, double-blind, placebo-controlled trial of glucosamine sulphate as an analgesic in osteoarthritis of the knee. Rheumatology (Oxford) 41: 279-284.

13. McAlindon T, Formica M, LaValley M, Lehmer M, Kabbara K (2004) Effectiveness of glucosamine for symptoms of knee osteoarthritis: results from an internet-based randomized double-blind controlled trial. Am J Med 117: 643649

14. Jun M, Shao Y, Ho CT, Koetter U, Lech S (2003) Structural identification of nonvolatile dimerization products of glucosamine by gas chromatographymass spectrometry, liquid chromatography-mass spectrometry, and nuclear magnetic resonance analysis. J Agric Food Chem 51: 6340-6346.

15. Akarasereenont $P$, Chatsiricharoenkul $S$, Pongnarin $P$, Sathirakul $K$ Kongpatanakul S (2009) Bioequivalence Study of $500 \mathrm{mg}$ Glucosamine Sulfate in Thai Healthy Volunteers. J Med Assoc Thai 92: 1234-1239.

16. U.S. Department of Health and Human Services, Food and Drug Administration, 
Citation: Akarasereenont P, Chatsiricharoenkul S, Pongnarin P (2012) Bioequivalence Study of 1,500 mg Glucosamine Sulfate in Thai Healthy Volunteers. J Bioequiv Availab 4: 091-095. doi:10.4172/jbb.1000119

Center for Drug Evaluation and Research (2001) Guidance for industry: statistical approaches to establishing bioequivalence. Washington, DC: HHS/ FDA/CDER.

17. Blume HH, Midha KK (1993) Bio-International 92, conference on bioavailability, bioequivalence, and pharmacokinetic studies. J Pharm Sci 82: 1186-1189.

18. U.S. Department of Health and Human Services Food and Drug Administration Center for Drug Evaluation and Research (CDER) (2003) Guidance for Industry: bioavailability and bioequivalence studies for orally administered drug products-general considerations.

19. Persiani S, Roda E, Rovati LC, Locatelli M, Giacovelli G, et al. (2005) Glucosamine oral bioavailability and plasma pharmacokinetics after increasing doses of crystalline glucosamine sulfate in man. Osteoarthritis Cartilage 13: 1041-1049.

20. Roda A, Sabatini L, Barbieri A, Guardigli M, Locatelli M, et al. (2006) Development and validation of a sensitive HPLC-ESI-MS/MS method for the direct determination of glucosamine in human plasma. J Chromatogr B Analyt Technol Biomed Life Sci 844: 119-126.

21. World Health Organization (WHO) (2006) WHO technical Report Series No. 937: WHO Expert Committee on Specifications for Pharmaceutical Preparations. Annex 7: 347-389.

22. The European Agency for the Evaluation of Medicinal Products Evaluation of Medicines for Human Use (2008) Guidance on the investigation of bioequivalence.

23. Walker RB, Kanfer I, Skinner MF (2006) Bioequivalence assessment of generic products: An innovative South African approach. Clinical Research and regulatory Affairs 23: 11-20.

24. Medicines Control Council (2007) Biostudies.

25. The European Agency for the Evaluation of Medicinal Products Evaluation of Medicines for Human Use (2001) Note for guidance on the investigation of bioavailability and bioequivalence. 